\title{
Lipases microbianas: Produção, propriedades e aplicações biotecnológicas
}

\section{Microbial lipases: Production, properties and biotechnological applications}

\author{
Josana Maria Messias ${ }^{1}$; Bruna Zucoloto da Costa ${ }^{2}$; Valéria Marta Gomes de Lima \\ Ellen Cristine Giese ${ }^{4}$; Robert Frans Huibert Dekker'; Aneli de Melo Barbosa ${ }^{6}$
}

\section{Resumo}

\begin{abstract}
Lipases pertencem ao grupo das hidrolases que catalisam a conversão de triacilgliceróis a ácidos graxos livres e glicerol. Possuem significante potencial biotecnológico como catalisadores em reações de síntese orgânica em meio não aquoso utilizando processos simplificados com altos rendimentos. A produção de lipases tem sido realizada, usualmente, por processo fermentativo submerso; entretanto, o processo em fase sólida também tem se mostrado promissor, quando são utilizados resíduos como fontes de substrato que são nutrientes de baixo custo. As lipases microbianas podem ser utilizadas como aditivos em alimentos para modificar e realçar as propriedades organolépticas, como também em detergentes para hidrolisar gorduras, no tratamento de efluentes oleosos, e ainda, nas indústrias farmacêuticas, de cosméticos, agroquímicas e oleoquímicas. Recentemente, as lipases têm sido utilizadas em reações de transesterificação para converter óleos em biodiesel. O objetivo deste trabalho foi revisar a literatura publicada sobre a produção, propriedades e aplicações das lipases microbianas e o seu papel biotecnológico na produção do biodiesel.
\end{abstract}

Palavras-chave: Enzimas. Enzimas microbianas. Aplicações de enzimas. Biodiesel.

\begin{abstract}
Lipases belong to the group of hydrolases that catalyze the hydrolysis of triacylglycerol lipids to free fatty acids and glycerol. They have significant potential biotechnological applications in catalyzing organic synthesis reactions in non-aqueous solvents using simplified procedures resulting in conversions of high yields. Lipase production has conventionally been performed by submerged fermentation; however, solid-state fermentation processes have been prominent when residues are used as substrates because they serve as low-cost nutrient sources. Microbial lipases can be used as additives in foods to modify and enhance organoleptic properties, as well as in detergents to hydrolyse fats in the treatment of oily effluents, and also have value for pharmaceutical, cosmetic, agrochemical, and oil chemical industries. More recently, they are used in transesterification reactions to convert plant seed oils into biodiesel. The objective of this work was to review the published literature on the production, properties and applications of microbial lipases, and its biotechnological role in producing biodiesel.
\end{abstract}

Key-words: Enzymes. Microbial enzymes. Enzyme applications. Biodiesel.

1 Mestre pelo Programa de Biotecnologia, Departamento de Bioquímica e Biotecnologia, Universidade Estadual de Londrina, Londrina-PR, Brasil, josana_mariamessias@yahoo.com.br.

2 Bolsista CNPq-PIBIC, Departamento de Bioquímica e Biotecnologia, Universidade Estadual de Londrina, Londrina-PR, Brasil, bzucoloto@gmail.com.

3 Docente do Depto de Ciências Biológicas, FCLA, UNESP, Assis, SP, Brasil; valeria@assis.unesp.br.

${ }^{4}$ Bolsista de pós-doutorado DFAIT, Biorefining Research Initiative, Lakehead University, Thunder Bay, ON, Canada, ellengiese@ gmail.com.

5 Diretor do Biorefining Research Initiative, Lakehead University, Thunder Bay, ON, Canada; rdekker@lakeheadu.ca.

6 Professora Associado C do Departamento de Bioquímica e Biotecnologia, Universidade Estadual de Londrina, Londrina-PR, Brasil, anelibarbosa@gmail.br. 


\section{Introdução}

Muitos processos tecnológicos utilizam catalisadores biológicos nas seqüências de conversão química. Estes biocatalisadores elevam consideravelmente a velocidade das reações, requerem condições brandas, são compatíveis com os substratos sintéticos e, em alguns casos, catalisam reações de síntese e degradação e podem apresentar seletividade quanto ao tipo de reação (WARNER; CANNON; DYE, 2004).

O uso de enzimas nas indústrias possibilita o desenvolvimento de processos tecnológicos tão eficientes quanto aos realizados pela natureza (HASAN; SHAH; HAMEED, 2006) e sem causar riscos ambientais. Consequentemente, a demanda mundial destas enzimas tem crescido anualmente, sendo mais de $90 \%$ do seu comércio efetuado pelos Estados Unidos, Europa e Japão. Existe uma expectativa de crescimento deste mercado, e espera-se para o ano de 2012, gastos superiores a 2,7 bilhões de dólares, com previsões futuras de aumento em torno de $4 \%$ (IYER; ANANTHANARAYAN, 2008).

Mais de 4000 enzimas são conhecidas e aproximadamente 200 são utilizadas comercialmente, sendo a grande maioria de origem microbiana. Pelo menos $75 \%$ de todas as enzimas industrializadas são hidrolases e destas, $90 \%$ são produzidas por micro-organismos através de processos fermentativos. Depois das proteases e carboidrases, as lipases constituem o terceiro maior grupo em vendas no mundo (JAEGER et al., 1997, SHARMA; CHISTI; BANERJEE, 2001).

As lipases (E.C.3.1.1.3) têm sido definidas como carboxilesterases que hidrolisam acilgliceróis de cadeia longa, ou seja, com cadeia acila constituída por mais de 10 átomos de carbono. Enzimas que apresentam a capacidade de hidrolisar apenas acilgliceróis de cadeia com menos de 10 carbonos são denominadas genericamente como esterases (VERGER, 1997; JAEGER; DIJKSTRA; REETZ, 1999; GHALY et al., 2010).

Os substratos naturais para lipases são óleos e gorduras contendo triacilgliceróis constituídos de ácidos graxos de cadeia longa, ou seja, ligações ésteres tríplices, enquanto esterases atuam sobre um único tipo de ligação éster, liberando ácidos graxos de baixo peso molecular (BIER, 1955; BROCKMAN, 1984). Deve-se enfatizar que a maioria das lipases pode hidrolisar os substratos de esterases, enquanto o inverso não é verdadeiro (JAEGER; DIJKSTRA; REETZ, 1999).

Dependendo das condições, as lipases também catalisam reações de síntese, comode esterificação, transesterificação (interesterificação, alcóolise e acidólise), aminólise (síntese de amidas) e lactonização (esterificação intramolecular), sendo que a atividade de água (aஸ) do meio reacional é um dos fatores determinantes para o equilíbrio da reação no sentido direto (hidrólise) ou inverso (síntese) (MAHADIK et al., 2002; JAEGER; EGGERT, 2002; SAXENA et al., 2003; REIS et al., 2009).

De maneira geral, as lipases não requerem cofatores, atuam em ampla faixa de $\mathrm{pH}$, são estáveis à altas temperaturas; possuem elevada especificidade e propriedades de régio, quimio e enantiosseletividade que fazem com que sejam altamente aplicáveis em processos industriais (VILLENEUVE et al., 2000; HASAN, SHAH, HAMEED, 2006).

\section{Fontes de obtenção de lipases}

As principais fontes de obtenção de lipases para aplicação industrial têm sido os microorganismos, embora estas sejam produzidas também por eucariotos superiores (plantas e animais). Tanto micro-organismos eucariotos (leveduras e fungos) como procariotos (bactérias, incluindo-se os actinomicetos), são produtores de 
lipases e suas propriedades variam de acordo com a procedência (SHARMA; CHISTI; BANERJEE, 2001; SAXENA et al., 2003).

Claude Bernard (1856) isolou pela primeira vez a lipase de suco pancreático e verificou que esta enzima solubilizava gotas de óleo. Anos mais tarde, o interesse pelas lipases microbianas aumentou devido à estabilidade e facilidade de obtenção em comparação com as de origem animal (HASAN; SHAH; HAMEED, 2006). Nos micro-organismos, as lipases podem apresentar atividade fosfolipídica, sendo utilizadas como mecanismo de defesa, visto que quando secretadas, proporcionam competição com a microflora; facilitam a digestão dos lipídeos e os ácidos graxos livres liberados auxiliam na adesão tecidual célula-célula e célula-hospedeiro (STEHR et al., 2003). A Tabela 1 exemplifica vários micro-organismos descritos como produtores de lipases.

\section{Produção de lipases microbianas}

A produção de lipases tem sido desenvolvida principalmente por fermentação submersa (FSM) devido aos aspectos de engenharia dominados e desenvolvidos; está associada ao crescimento microbiano e consequentemente, às variações da composição e condições do cultivo (SHARMA; CHISTI; BANERJEE, 2001). Estas enzimas também podem ser produzidas por fermentação em estado sólido (FES), no qual são utilizados substratos insolúveis com baixas porcentagens de água em sua composição. Tais substratos atuam como fonte de nutrientes e como suporte fisiológico (PANDEY, 2003).

Existem vantagens e desvantagens da FES quando comparada com a FSM, quanto à produção de enzimas. Na FES os substratos geralmente apresentam baixo custo, dado ao reaproveitamento de resíduos agroindustriais, que possuem baixo teor de umidade e proporcionam baixo risco de contaminação no processo fermentativo. As desvantagens da FES estão na não homogeneidade do meio de cultivo e na limitação de transferência de massa, além da dificuldade de monitorar e controlar os parâmetros operacionais. Dentre as vantagens da FSM, está a homogeneidade do sistema que possibilita transferência de calor mais eficiente e a facilidade de controlar parâmetros como $\mathrm{pH}$, temperatura e oxigenação. Entretanto, a principal desvantagem está no custo elevado do processo, que pode inviabilizar a produção em escala industrial (BIANCHI; MORAES; CAPALBO, 2001; SINGHANIA et al., 2009).

A produção de lipase via FES tem sido relatada principalmente por fungos filamentosos e pouco por bactérias e leveduras; utilizando resíduos da agroindústria.

Torta de semente de Jatropha curcas (pinhão manso) foi utilizada como substrato para produção de lipases e proteases pela bactéria Pseudomonas aeruginosa por FES. A máxima produção de lipase foi $1084 \mathrm{U} /$ grama de substrato seco (U/g ss) com 50\% de umidade do substrato, $120 \mathrm{~h}$ de cultivo, $\mathrm{pH} 7,0$, com o meio enriquecido com maltose e $\mathrm{NaNO}_{3}$ (MAHANTA; GUPTA; KHARE, 2008). A bactéria Burkholderia cepacia também produziu lipase via FES, e a atividade de $108 \mathrm{U} / \mathrm{g}$ ss foi obtida em $72 \mathrm{~h}$ de cultivo, sendo o meio de fermentação constituído por farelo de trigo, enriquecido com $5 \%$ de óleo de milho. O fermentado sólido obtido foi liofilizado e utilizado como catalisador em reações de esterificação e transesterificação com resultados positivos (FERNANDES et al., 2007). 
Tabela 1. Micro-organismos produtores de lipases relatados na literatura (1965 - 2011).

\begin{tabular}{|c|c|c|}
\hline$\overline{\text { Fonte }}$ & Micro-organismos & Referências \\
\hline Arqueobactérias & Natronococcus sp. & BOUTAIBA et al., 2006 \\
\hline Bactérias & Bacillus stearothermophilus MC 7 & KAMBOUROVA et al., 2003 \\
\hline \multirow[t]{7}{*}{ (Gram-positivas) } & B. megaterium & LIMA et al., 2004 \\
\hline & Burkholderia glumae & KHATTABI et al., 2003 \\
\hline & B. cepacia & FERNANDES et al., 2007 \\
\hline & Ralstonia sp. & YOO et al., 2011 \\
\hline & Staphylococcus aureus & SHAH; WILSON, 1965 \\
\hline & S. epidermidis & SIMONS et al., 1998 \\
\hline & S. xylosus & MOSBAH et al., 2007 \\
\hline Bactérias & Chromobacterium viscosum & JAEGER; REETZ, 1998 \\
\hline \multirow[t]{5}{*}{ (Gram-negativas) } & Photobacterium lipolyticum & YANG; SOHN; KIM, 2009 \\
\hline & Pseudomonas aeruginosa & JAEGER et al., 1997 \\
\hline & P. mendocina & JAEGER; REETZ, 1998 \\
\hline & P. fluorescens HU380 & KOJIMA; SHIMIZU, 2003 \\
\hline & Serratia marcescens & JAEGER et al., 1997 \\
\hline \multirow[t]{2}{*}{ Actinomicetos } & Streptomyces cinnamomeus Tü89 & $\begin{array}{l}\text { SOMMER; BORMANN; } \\
\text { GÖTZ, } 1997\end{array}$ \\
\hline & S. coelicolor A3(2) & CÔTÉ; SHARECK, 2008 \\
\hline Fungos & Candida rugosa & DALMAU et al., 2000 \\
\hline \multirow[t]{4}{*}{ leveduriformes } & C. cylindracea & BROZZOLI et al., 2009 \\
\hline & Torulopsis ernobii & $\begin{array}{l}\text { YOSHIDA; MOTAI; } \\
\text { ICHISHIMA, } 1968\end{array}$ \\
\hline & Issatchenkia orientalis & $\begin{array}{l}\text { COSTAS; DEIVE; LONGO, } \\
2004\end{array}$ \\
\hline & Yarrowia lipolytica & DOMÍNGUEZ et al., 2003 \\
\hline Fungos & Antrodia cinnamomea & LIN; WANG; SUNG, 2006 \\
\hline \multirow[t]{12}{*}{ filamentosos } & Alternaria sp. & TOM; CRISAN, 1975 \\
\hline & Aspergillus carneus & SAXENA et al., 2003 \\
\hline & A. terreus & GULATI et al., 1999 \\
\hline & A. niger & EDWINOLIVER et al., 2010 \\
\hline & A. oryzae & TOIDA et al., 2000 \\
\hline & Beauveria bassiana & $\begin{array}{l}\text { HEGEDUS; } \\
\text { KHACHATOURIANS, } 1988\end{array}$ \\
\hline & Botryosphaeria rhodina & MESSIAS et al., 2009 \\
\hline & B. ribis & MESSIAS et al., 2009 \\
\hline & Botrytis cinerea & COMMÉNIL et al., 1999 \\
\hline & Cunninghamella verticillata & GOPINATH et al., 2002 \\
\hline & Geotrichum sp. & BURKET et al., 2004 \\
\hline & Fusarium globulosum & GULATI et al., 2005 \\
\hline
\end{tabular}


Continuação Tabela 1

\begin{tabular}{ll} 
F. oxysporum & PRAZERES; CRUZ; PASTORE, 2006 \\
Mucor circinelloides & SZCZESNA-ANTCZAK et al., 2006 \\
Penicillium aurantiogriseum & LIMA et al., 2003 \\
P. citrinum & MIRANDA et al., 1999 \\
P. restrictum & CAMMAROTA; FREIRE, 2006 \\
P. simplicissimum & GUTARRA et al., 2007 \\
P. verrucosum & KEMPKA et al. 2008 \\
Rhizomucor miehei & JAEGER; REETZ, 1998 \\
Rhizopus arrhizus & LI; WANG; TAN, 2006 \\
$R$. chinensis & SUN; XU, 2009 \\
$R$. delemar & AÇIKEL, ERŞAN, AÇIKEL, 2010 \\
$R$. homothallicus & DIAZ et al., 2006 \\
$R$. oryzae & ESSAMRI; DEYRIS; COMEAU, 1998 \\
Thermomyces lanuginosa & FERNANDES et al., 2004 \\
Trichoderma viride & KASHMIRI; ADNAN; BUTT, 2006 \\
\hline
\end{tabular}

Domíngues e colaboradores (2003) avaliaram o potencial de resíduos agroindustriais (farelo de cevada e castanha triturada) como substratos para a produção de lipase por FES, utilizando-se a levedura Yarrowia lipolytica e obtiveram melhores resultados com estes resíduos do que com o suporte inerte de esponja de náilon. A produção de lipases por vinte e nove leveduras isoladas do filoplano de Hibiscus rosasinensis foi avaliada por Bussamara e colaboradores (2010). As cepas que apresentaram maior produção de lipases foram Pseudozyma hubeiensis HB85A, Debaryomyces occidentalis HB83 e Cryptococcus sp. HB80 quando na presença de Tween-20.

Em relação aos fungos filamentosos, Kamini; Mala; Puvunakrishnan (1998) avaliaram a produção de lipase por Aspergillus niger utilizando torta de gergelim como substrato e obtiveram $363,6 \mathrm{U} / \mathrm{g}$ ss em $72 \mathrm{~h}$ de cultivo. Em outro trabalho, este mesmo fungo foi cultivado em farelo de trigo contendo $1 \%$ de óleo de oliva e o pico de produção de lipase ácida por $A$. niger foi $630 \mathrm{U} / \mathrm{g}$ ss (MAHADIK et al., 2002). A mistura de substratos para a produção de lipases por A. niger MTCC 2594, foi avaliada utilizando-se torta de gergelim e também o farelo de trigo. A máxima produção 384,3 \pm 4,5 U/g ss foi obtida com a proporção de $3: 1(\mathrm{~m} / \mathrm{m})$ constituída por torta de gergelim e farelo de trigo (MALA et al., 2007).

Torta de babaçu foi avaliada como substrato para a produção de lipase por uma linhagem brasileira de Penicillium restrictum. Os maiores títulos de atividade de lipase, 27,8 ou $30,3 \mathrm{U} / \mathrm{g}$ ss, foram obtidos quando o meio foi enriquecido com peptona $1 \%(\mathrm{~m} / \mathrm{m})$ ou óleo de oliva $\%$ (v/m), respectivamente (GOMBERT et al., 1999). Di Luccio e colaboradores (2004) estudaram a produção de lipases por $P$. simplicissimum utilizando torta de soja; o efeito da temperatura, umidade e de fontes de carbono suplementares foram avaliados e a máxima atividade de lipase foi $21 \mathrm{U} / \mathrm{g}$ ss.

A produção de lipase por Rhizopus oligosporous foi investigada em diferentes tortas (amêndoa, coco, mostarda e soja), além de palha de arroz e farelo de trigo. A maior atividade foi $48 \mathrm{U} / \mathrm{g}$ ss quando se utilizou a torta de amêndoa (UL-HAQ, IDRESS; RAJOKA, 2002). Uma cepa de $R$. homothallicus produziu lipase em bagaço de cana umedecido com meio líquido. A produção foi aumentada através da modificação dos nutrientes do meio de cultivo; os nutrientes que mais influenciaram o crescimento fúngico e produção da 
enzima foram uréia, óleo de oliva e micro-elementos $\left(\mathrm{MnCl}_{2}, \mathrm{CoSO}_{4}, \mathrm{CuSO}_{4}, \mathrm{ZnSO}_{4}\right.$ e EDTA). A máxima atividade (826 U/g ss) foi obtida em somente $12 \mathrm{~h}$ de incubação (RODRIGUEZ et al.; 2006). Esta mesma espécie fúngica produziu lipase mais termoestável via FES, utilizando-se bagaço de cana umedecido com solução nutriente contendo óleo de oliva, do que por FSM contendo milhocina e peptona no meio de sais (DIAZ et al., 2006).

Sun; Xu (2008) investigaram a produção de lipase de $R$. chinensis via FES utilizando farinha e farelo de trigo $(3: 2 \mathrm{~m} / \mathrm{m})$. A máxima atividade $(24,5 \mathrm{U} / \mathrm{kg} \mathrm{ss})$, após $72 \mathrm{~h}$ de cultivo, foi obtida com umidade inicial de $70 \%$, $\mathrm{pH}$ inicial de 6,5 , peptona $(2 \% \mathrm{~m} / \mathrm{m})$ e óleo de oliva $(2 \% \mathrm{v} / \mathrm{m})$ como indutor. Os autores compararam as lipases extraídas da membrana celular deste mesmo micro-organismo cultivado via FES e também FSM; a lipase de cada um dos processos fermentativos foi purificada e ambas apresentaram atividade máxima a $40{ }^{\circ} \mathrm{C}$ e $\mathrm{pH} 8,0$. As lipases apresentaram diferença na massa molecular aparente (62 e $40 \mathrm{kDa}$, respectivamente), sendo que a enzima obtida via FES foi mais termoestável e mais tolerante ao $\mathrm{pH}$ (SUN; $\mathrm{XU}, 2009)$.

A produção de lipase por Rhizomucor pusillus e Rhizopus rhizopodiformis via FES foi avaliada utilizando-se como substratos torta de azeitona e bagaço de cana-de-açúcar. As maiores atividades 79,6 $\mathrm{U} / \mathrm{g}$ ss e 20,24 U/g ss, respectivamente, foram obtidas com uma mistura de $50 \%$ de ambos os substratos (CORDOVA et al., 1998).

O fungo Penicillium sp. foi cultivado tanto via FES quanto FSM utilizando-se farelo de soja e azeite de oliva, respectivamente, como substratos. As atividades de lipase foram 15,2 U/ml para a primeira e 11,3 U/ $\mathrm{ml}$, para a segunda. Entretanto, os valores de $\mathrm{pH}$ e temperatura ótimos para ambos os extratos brutos variaram, sendo 5,5 e $47^{\circ} \mathrm{C}$ para a obtida por FES e 7,0 e $37{ }^{\circ} \mathrm{C}$ para a obtida por FSM. A atividade de lipase obtida via FES apresentou maior estabilidade em comparação com a obtida por FSM (WOLSKI et al., 2009). A Tabela 2 apresenta alguns fungos produtores de lipases e compara as condições e composição dos meios de cultivo.

A análise econômica da produção de lipase por $P$. restrictum via FES e FSM foi descrita por Castilho e colaboradores (2000), que enfatizaram a FES como um processo mais atrativo do ponto de vista econômico, apresentando um custo de investimento $78 \%$ menor do que a FSM.

\section{Determinação da atividade lipase}

A atividade de lipase tem sido determinada através da quantificação dos ácidos graxos liberados durante a hidrólise mediada pela enzima. Estes produtos podem ser determinados por métodos físico-químicos avaliando-se o desaparecimento do substrato ou a formação dos produtos da reação. Dentre os métodos que avaliam o desaparecimento do substrato podem ser citados a nefelometria e turbidimetria, tensiometria interfacial, microscopia de força atômica e espectroscopia de infravermelho. Os principais métodos que avaliam o aparecimento dos produtos da reação de hidrólise compreendem ensaios indiretos da liberação de prótons (indicadores coloridos e titulometria), análise de ácidos graxos liberados a partir de ésteres carboxílicos derivados do glicerol (ensaios colorimétricos, fluorimétricos, cromatográficos, enzimáticos, microscopia eletrônica por detecção in situ) e análise de ácidos graxos liberados a partir de ésteres carboxílicos sintéticos (ensaios radioativos, colorimétricos, fluorimétricos) e métodos imunológicos, entre outros (BEISSON et al., 2000; GUPTA et al., 2003; HASAN, SHAH, HAMEED, 2009).

Um método útil para a seleção de micro-organismos lipolíticos é o zimograma, que consiste na detecção qualitativa da atividade de lipase secretada em meio sólido contendo ágar, meio de cultivo e substrato (tributirina, trioleína, óleo de oliva, Tween-80), no qual se pode observar a formação de halos claros ao redor das colônias, que correspondem às zonas do substrato hidrolisado. Quando utilizado Rodamina B como substrato, é possível observar a formação de halos 
fluorescentes sob luz UV (KOUKER; JAEGER, 1987; SHARMA; CHISTI; BANERJEE, 2001; BECKER et al., 2005).

Dentre os vários métodos disponíveis para acompanhar a atividade de lipase presente no meio fermentativo, os mais utilizados são os colorimétricos que utilizam substratos sintéticos como ésteres de ácidos graxos de $p$-nitrofenila (acetato, butirato, caproato, caprato, palmitato e esterato) e o titulométrico (pH STAT) que usa a trioleína como substrato padrão. O óleo de oliva é uma alternativa de baixo custo para ser utilizado como substrato e contém em média $70 \%$ de trioleína (GUPTA et al., 2003; LIMA et al., 2004; MESSIAS et al., 2009).

\section{Características cinéticas e físico-químicas das lipases microbianas}

O fenômeno mais conhecido originado de estudos cinéticos de reações catalisadas pela lipase éa "ativação interfacial", a qual é responsável pelo aumento da atividade lipolítica em função dos substratos insolúveis. Neste caso, a emulsão formada causa uma mudança conformacional na estrutura quaternária da enzima (SAXENA et al., 2003).

As lipases possuem baixa atividade hidrolítica quando seus substratos (ésteres, por exemplo) são dissolvidos em meio aquoso e são monômeros. Um aumento da atividade é pronunciado quando a concentração do substrato atinge o limite de solubilidade e ocorre a separação da fase lipídica da fase aquosa (HASAN, SHAH, HAMEED, 2009; REIS et al., 2009).

A determinação da estrutura tridimensional da lipase (obtida por difração de raio-X) fornece uma compreensão para a ativação interfacial. $\mathrm{O}$ sítio ativo das lipases é coberto por uma cadeia peptídica denominada tampa, de natureza hidrofóbica. Quando a tampa encontra uma interface lipídeo-água, há interação entre ambas e esta sofre uma alteração conformacional (a tampa se move alterando a forma fechada da enzima para a forma aberta) expondo o sítio ativo e permitindo a catálise (BRADY et al., 1990; WINKLER; D'ARCY; HUNZIKER, 1990; SCHRAG et al., 1991; HOLMQUIST, 2000).

O centro ativo fica acessível ao substrato e, ao mesmo tempo, a lipase expõe uma larga superfície hidrofóbica que facilita a ligação à interface (JAEGER; REETZ, 1998; SECUNDO et al., 2006). Algumas lipases não apresentam o sítio ativo recoberto pela tampa e não precisam da interface para desempenhar sua atividade hidrolítica, como é o caso das cutinases, descritas como as menores lipases de estrutura conhecida, encontradas em diversos micro-organismos fitopatogênicos, como Fusarium solani e Alternaria solani (CYGLER; SCHRAG, 1997; LONGHI et al., 1997; MARCHI; BORGES; MIZUBUTI, 2006).

Os trabalhos sobre mecanismos de adsorção das lipases e a catálise em sistemas heterogêneos relacionados às propriedades físico-químicas da interface, primordialmente foram reportados por Sarda; Desnuelle (1958). Estes demonstraram que a cinética de lipases em emulsões dependia da interface e que poderia seguir o modelo de Michaelis-Menten se o termo "concentração de substrato" fosse substituído pela área interfacial.

De acordo com Sharma, Chisti, Banerjee (2001), as reações lipolíticas ocorrem na interface águalipídeo e podem impedir que as cinéticas das reações enzimáticas sejam descritas pelas equações do tipo Michaelis-Menten, que só são válidas se a reação catalítica ocorrer em fase homogênea.

A estrutura química e as características cinéticas das lipases microbianas variam dependendo do microorganismo, gênero, espécie e também da cepa. Lima e colaboradores (2004) relataram que uma lipase de Bacillus megaterium apresentou temperatura ótima de reação a $55^{\circ} \mathrm{C}$, enquanto outras lipases bacterianas apresentaram atividade máxima acima dos $70^{\circ} \mathrm{C}$, como as de Bacillus stearothermophilus MC 7 (KAMBOUROVA et al., 2003), chegando até mesmo aos $90^{\circ} \mathrm{C}$, como a carboxilesterase da arqueobactéria Pyrobaculum calidifontis (HOTTA et al., 2002). 


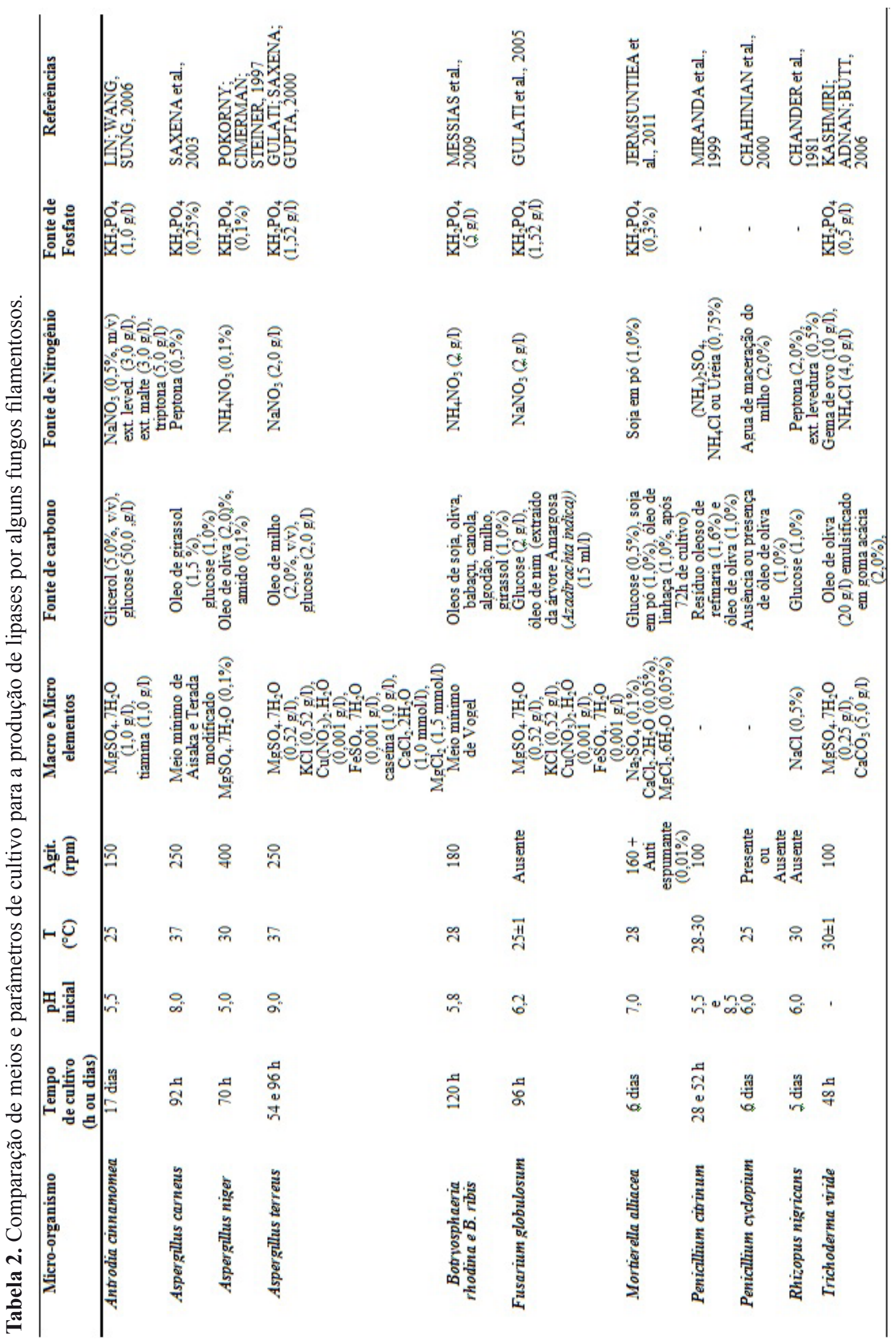


Aestabilidade térmica é uma das características requeridas para as enzimas com aplicação industrial, visto que muitos processos utilizam faixas extremas de temperatura. Lipases oriundas de bactérias termofílicas tem papel importante na indústria devido a elevada estabilidade em altas temperaturas (JAEGER; REETZ, 1998). Lipases psicrofílicas, também merecem atenção, pois apresentam elevada atividade em temperaturas muito baixas; propriedade esta de grande importância na síntese de determinados intermediários orgânicos quirais termossensíveis. Micro-organismos adaptados ao frio são fontes potenciais de lipases psicrofílicas (JOSEPH; RAMTEKE; THOMAS, 2008).

Não existeum protocolo padrão para determinar a termoestabilidade das lipases microbianas, o que dificulta a comparação entre elas. A lipase da bactéria halofílica Natronococcus sp. incubada durante $60 \mathrm{~min}$ a $50^{\circ} \mathrm{C}$, permaneceu com $90 \%$ da atividade residual (BOUTAIBA et al., 2006); a de Streptomyces coelicolor A3(2) após 30min, a $70^{\circ} \mathrm{C}$, apresentou atividade residual em torno de 60-80 \% (CÔTÉ; SHARECK, 2008); a $100{ }^{\circ} \mathrm{C}$ e durante $2 \mathrm{~h}$, a carboxilesterase de Pyrobaculum calidifontis não diminuiu sua atividade (HOTTA et al., 2002).

Várias lipases bacterianas atuam em $\mathrm{pH}$ alcalino. Isto foi observado para espécies de Bacillus stearothermophilus MC7 ( $\mathrm{pH} 7,5-9,0$ ) (KAMBOUROVA et al., 2003), Pseudomonas fluorescens HU380 ( $\mathrm{pH}$ 8,5) (KOJIMA; SHIMIZU, 2003) e Staphylococcus xylosus $(\mathrm{pH}$ 8,5) (MOSBAH et al., 2007). Existem lipases que atuam em ampla faixa de $\mathrm{pH}$, como a de Staphylococcus epidermidis (pH entre 2,0 e 10,0) (SIMONS et al., 1998) e Bacillus megaterium (pH entre 4,0 e 12,0) (RUIZ et al., 2002). Já a lipase de outra linhagem de Bacillus megaterium apresentou atividade em uma faixa de $\mathrm{pH}$ mais restrita (entre 5,0 e 7,0) (LIMA et al., 2004).

De modo geral, a massa molecular das lipases microbianas varia entre 20 e $60 \mathrm{kDa}$ (MALA; TAKEUCHI, 2008). A lipase de menor estrutura conhecida pertence à bactéria anaeróbica Propionibacterium acidi-propionici que apresentou massa molecular entre $6,0-8,0 \mathrm{kDa}$ (SARADA; JOSEPH, 1992). Uma exceção de massa molecular mais alta, pode ser representada pelas lipases das bactérias psicrotróficas isoladas de sedimentos de mar profundo do oeste Pacífico, Psychrobacter sp. wp37 e Pseudoalteromonas sp. wp27, cuja massa molecular foi $85 \mathrm{kDa}$ (ZENG et al., 2004). A Tabela 3 exibe características físico-químicas de algumas lipases descritas na literatura.

\section{Aplicações das lipases}

Embora as lipases sejam produzidas por vegetais, animais e micro-organismos, os fungos são valorizados porque produzem enzimas extracelulares, o que facilita a recuperação destas do meio fermentativo. As fontes fúngicas têm sido preferenciais, não devido às suas melhores características em relação à lipases bacterianas, mas porque, na sua maioria, não são nocivas à saúde humana e reconhecidas como GRAS (Generally Regarded As Safe) (JAEGER et al., 1994). Fungos de diversos gêneros são bons produtores de lipases e têm sido estudados do ponto de vista acadêmico e industrial (Tabela 1).

As lipases se destacam entre as hidrolases devido as suas múltiplas aplicações, sendo utilizadas nas indústrias de detergentes, medicamentos, alimentos (panificação, queijos, chás), têxteis, polpa e papel, curtumes, cosméticos, biodiesel, biossensores e também no tratamento de efluentes (JAEGER; REETZ, 1998; HOUDE; KADEMI; LEBLANC, 2004; HASAN; SHAH; HAMEED, 2006).

Uso de lipases na indústria de detergentes 
Uma das maiores aplicações industriais das lipases tem sido como aditivos em detergentes (HASAN; SHAH; HAMEED, 2006), pois facilitam os processos de limpeza, hidrolisando os lipídeos e favorecendo a solubilização destas biomoléculas em água (PANDEY et al., 1999). Estas hidrolases são adicionadas em detergentes líquidos e sólidos, domésticos e industriais, e devem ser estáveis em $\mathrm{pH}$ alcalino, em altas temperaturas, e não devem sofrer desnaturação pela ação de surfactantes. A principal vantagem do uso de lipases nos detergentes em substituição aos polissulfatos está na biodegradabilidade e redução dos impactos ambientais, incluindo-se a vida aquática (HASAN; SHAH; HAMEED, 2006).

\section{Lipases na indústria química e farmacêutica}

O uso de lipases nas indústrias químicas e farmacêuticas vem crescendo nos últimos anos, consideravelmente. Além de catalisarem reações de hidrólise regiosseletiva, acilação e transesterificação, uma crescente variedade de processos enantiosseletivos têm sido relatados. Estas hidrolases catalisam reações sobre substratos pró-quirais e resolução cinética de misturas racêmicas. Os grupos funcionais sobre os quais as lipases atuam variam grandemente: álcoois e ésteres carboxílicos quirais ou próquirais, cianonidrinas, cloridrinas, dióis, $\alpha$ e $\beta$-hidroxi-ácidos, aminas, diaminas e aminoálcoois (JAEGER; DIJKSTRA; REETZ, 1999; JAEGER; EGGERT, 2002).
A produção de lactonas sintéticas por lipases constitui outra importante aplicação destas enzimas na indústria farmacêutica. Lactonas naturais (octalactinas), isoladas de Streptomyces apresentam atividade citotóxica contra células de melanoma e de tumor de cólon. Outras lactonas (nonanolídeos), isoladas de Penicillium, apresentam efeito inibitório sobre a síntese do colesterol (LONGO JÚNIOR; BOMBONATO; FERRAZ, 2007).

Lipases também podem ser utilizadas como agentes terapêuticos, no tratamento de insuficiência pancreática exócrina, cuja suplementação é feita com pancreatina (extraída de pâncreas suíno ou bovino) ou pancrelipase (maior nível de pureza e extraída somente de pâncreas suíno). Entretanto, são inativadas devido à sua instabilidade em $\mathrm{pH}$ inferior a $4 \mathrm{e}$ hidrólise proteolítica, o que obriga à utilização de altas doses, administração repetida e o uso concomitante de antiácido. Outra limitação do uso de extrato de pâncreas como fonte de enzima é a ocorrência de distúrbios gastrintestinais e hiperuricosúria ou hiperuricemia devido ao conteúdo de purina do produto (LAYER; KELLER; LANKISCH, 2001; LAYER; KELLER, 2003). Lipases microbianas estáveis e ativas em $\mathrm{pH}$ ácido, resistentes à hidrólise por proteases digestivas e com atividade na presença de sais biliares, podem representar alternativas terapêuticas superiores e existem patentes sobre este assunto (SVENDSEN et al., 2008). 


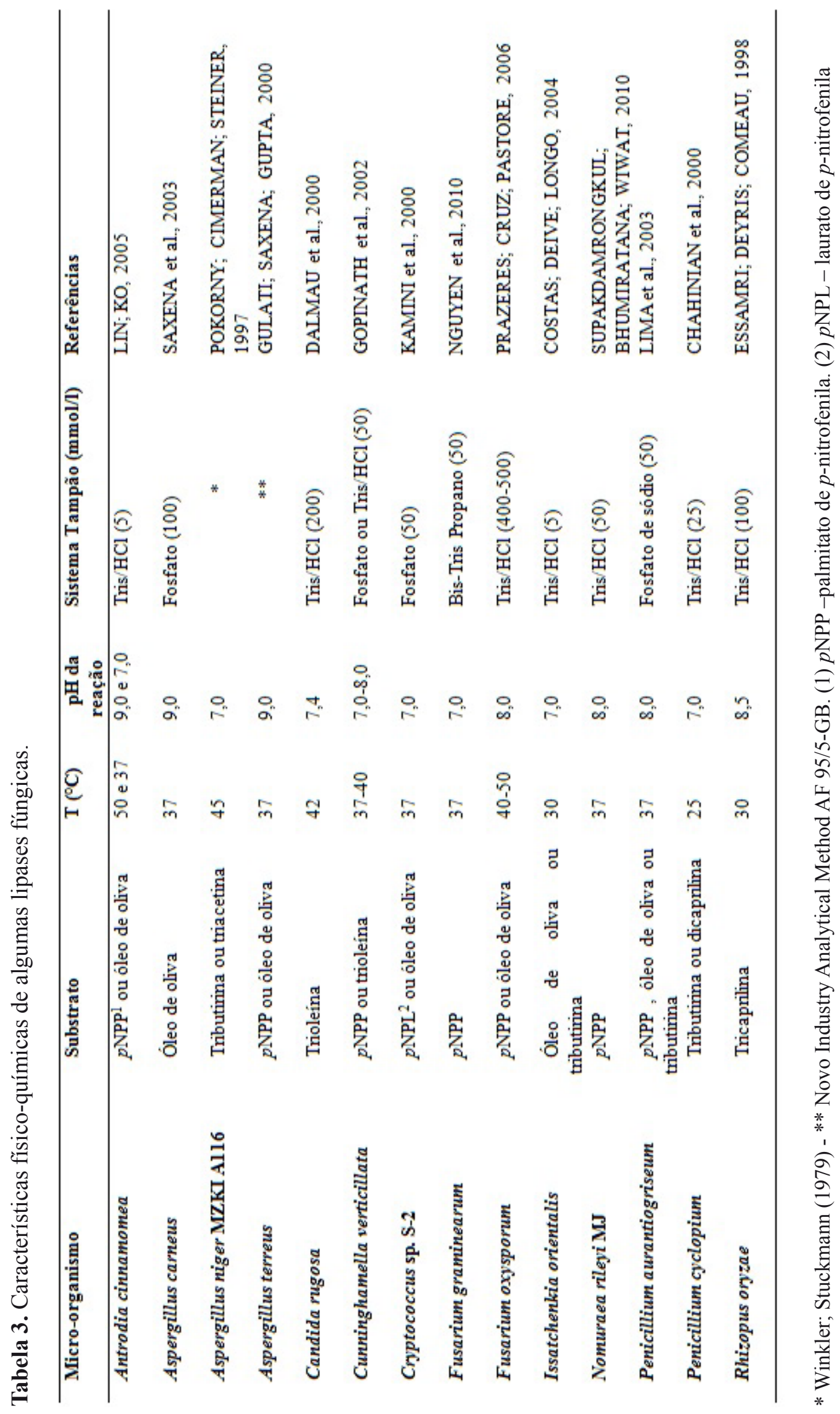




\section{Indústria de alimentos}

Os ácidos graxos livres conferem sabor e aroma peculiares aos alimentos de acordo com o tamanho da cadeia carbônica e grau de insaturação. São obtidos a partir da hidrólise enzimática parcial ou seletiva de óleos e gorduras de diferentes alimentos. As lipases também têm sido empregadas na obtenção de ácidos graxos essenciais como o ácido linoléico e o ácido $\alpha$-linolênico, (MALCATA et al., 1990; CARVALHO et al., 2003).

Quando imobilizadas na forma de biossensores, as lipases são utilizadas na detecção de ácidos graxos livres e triacilgliceróis em óleos e azeites (REJEB et al., 2007). Também são aplicadas na desacetilação da quitosana para a produção de oligossacarídeos (LEE; XIA; ZHANG, 2008) e na incorporação de antioxidantes em óleos (SENANAYAKE; SHAHIDI, 2004).

A partir dos anos 90 surgiram evidências dos efeitos deletérios da gordura trans à saúde humana. Esse tipo de lipídeo pode estar presente nos alimentos devido ao processo de hidrogenação parcial de gordura insaturada e é usado, por exemplo, para fabricação de margarinas a partir de óleos vegetais. Por isso, a hidrogenação parcial tem sido substituída por outros métodos de modificação de óleos e gorduras, como o fracionamento, interesterificação e hidrogenação total. A interesterificação envolve o rearranjo das cadeias de ácidos graxos em um triacilglicerol, podendo ser promovida por catálise alcalina ou enzimática. A catálise alcalina produz uma mistura de triacilgliceróis, nos quais os ácidos graxos são distribuídos ao acaso, enquanto a catálise enzimática, com lipases, é específica, alterando os ligantes das posições 1 e 3 , sem alterar a ligação do ácido graxo presente na posição 2 do glicerol (UPRITCHARD et al., 2005).

Shin; Akoh; Lee (2010) utilizaram lipases na interesterificação de triacilgliceróis da manteiga com óleo de palma, reduzindo o teor de gordura saturada, sem produzir gordura trans. Alim e colaboradores (2008) utilizaram lipase para obter gordura com maior ponto de fusão pela reação entre estearina (18:0), ácido linoléico (18:2) e óleo fracionado de farelo de arroz.

As lipases tem sido aplicadas na produção do emulsificante ricinoleato de poliglicerol (BÓDALO et al., 2009), no tratamento de resíduos gordurosos de indústrias de ração animal (JEGANATHAN; NAKHLA; BASSI, 2007), como suplemento na alimentação de não-ruminantes, suprimindo deficiências enzimáticas e melhorando a utilização dos nutrientes das matérias-primas que apresentam difícil digestibilidade para os animais (FERREIRA et al., 2005).

\section{Biodiesel}

O uso de novas tecnologias biocombustíveis (produção de bioetanol, biodiesel) é uma alternativa viável para substituir o petróleo por se tratar de uma tecnologia verde, que não polui e não contribui para o aumento de $\mathrm{CO}_{2}$ na atmosfera, responsável pelo aumento da temperatura terrestre (DÜBEREINER; BALDANI, 1998).

A lei brasileira $n^{\circ} 11.097$, de 13 de janeiro de 2005 dispôs sobre a introdução do biodiesel na matriz energética brasileira e sancionou 5\% (em volume) como percentual mínimo obrigatório de adição de biodiesel ao óleo diesel, comercializado ao consumidor final em qualquer parte do território nacional. O prazo para aplicação desta lei foi de 8 anos, sendo que após 3 anos de sua publicação, $2 \%$ de biodiesel deveria ser adicionado ao óleo diesel. Esta mistura já está em vigor e o volume de biodiesel adicionado deverá ser elevado para $5 \%$ a partir de 2013, conforme as diretrizes do Programa Nacional de Produção e Uso de Biodiesel (PNPB) do Ministério de Minas e Energia (2010).

No início de 2010, a produção de biodiesel atingiu 231 milhões de litros, considerada um recorde brasileiro. As matérias-primas utilizadas na produção deste biocombustível são óleo de soja $(82,9 \%)$, gordura bovina $(12,1 \%)$, óleo de algodão 
$(2,4 \%)$ e outros materiais graxos $(2,6 \%)$. O centrooeste é a região que concentra a maior produção de biodiesel $(42,6 \%)$, seguido pela região sul $(23,2$ $\%)$, sudeste $(18,5 \%)$, nordeste $(11,1 \%)$ e norte $(4,6$ \%) (BRASIL, 2010).

Existem várias plantas alternativas que produzem óleos, os quais podem ser extraídos e utilizados para a produção de biodiesel, principalmente na faixa tropical do planeta. Entretanto, em algumas áreas gélidas da Patagônia, iniciativas foram tomadas para produzir biodiesel utilizando-se óleo de algas marinhas. Além dos óleos vegetais, gorduras de peixes (sardinha), bovinos, frangos e suínos podem ser aproveitadas para a produção do combustível (OLIVEIRA, 2007).

Embora os óleos vegetais possam ser usados como combustíveis, sua alta viscosidade resulta em pobre atomização na câmara de combustão e causa problemas como formação de depósitos. A conversão de triacilglicérois em acil-ésteres por transesterificação com alcoóis (metanol ou etanol) tem sido proposta para permitir a utilização de óleos vegetais como fonte de combustível renovável e alternativo ao petróleo, sem os problemas técnicos do uso do óleo in natura (NIELSEN; BRASK; FJERBAEK, 2008).

Tanto a transesterificação de triacilgliceróis quanto a esterificação de ácidos graxos, realizadas para a síntese de ésteres metílicos ou etílicos (ambos usados como biodiesel), podem ser obtidas por catálise química ou enzimática. A catálise química, apesar de bons rendimentos (acima de 90\%), em 2-3h de reação necessita de temperaturas elevadas $\left(130-160{ }^{\circ} \mathrm{C}\right)$ e gera resíduos tóxicos além de produzir toneladas de glicerina impura e com baixo valor comercial. A catálise enzimática, por outro lado, acontece em condições brandas e a glicerina produzida tem alta pureza, alcançando valores de mercado mais elevados (NIELSEN; BRASK; FJERBAEK, 2008; RANGANATHAN; SRINIVASAN; MUTHUKUMAR, 2008).

Bajaj e colaboradores (2010) revisaram a produção de biodiesel por transesterificação enzimática e relataram rendimentos entre 92 e 98,4 \% utilizando-se lipases de Pseudomonas fluorecens, Cromobacterium viscosum, Penicillium expansum e Candida antarctica.

Foi isolada uma lipase de Ralstonia sp., estável na faixa de $\mathrm{pH}$ entre 7,0-12,0, com atividade ótima a $50-55^{\circ} \mathrm{C}$. A produção de biodiesel (entre 12 e $36 \mathrm{~h}$ ) foi mais eficiente em óleo de palma do que no de soja, com teor de água de $20 \%$ e $5 \%$ de metanol na reação (pH 8,0) (YOO et al., 2011).

No processo de produção de biodiesel, por via enzimática, podem ser utilizadas lipases livres ou imobilizadas. Noureddini; Gao; Philkana (2005) imobilizaram a lipase de Pseudomonas cepacia para a produção de biodiesel a partir de óleo de soja. Os alcoóis utilizados foram o metanol e etanol. Fatores como a massa da enzima, concentração de água e álcool na reação, estabilidade térmica e temperatura na transesterificação foram investigados. A reação ocorreu a $35{ }^{\circ} \mathrm{C}$ e foram utilizados $10 \mathrm{~g}$ de óleo de soja e $475 \mathrm{mg}$ de lipase. Duas proporções molares: 1:7,5 (óleo /metanol) com adição de $0,5 \mathrm{~g}$ de água e 1:15,2 (óleo/etanol) com adição de $0,3 \mathrm{~g}$ de água, foram as condições ótimas do processo. Após 1h, houve formação de $67 \%$ de ésteres metílicos e etílicos.

Células imobilizadas de Rhizopus oryzae foram utilizadas para a produção do biodiesel por Hama e colaboradores (2007). Um reator do tipo "packedbed" usando células inteiras do fungo $\left(30{ }^{\circ} \mathrm{C}\right)$ foi desenvolvido para a produção do combustível por metanólise a partir do óleo de soja. Alta concentração do éster metílico (90\%) foi alcançada na razão de $25 \mathrm{l} / \mathrm{h}$ no primeiro ciclo e foi mantida $80 \%$ da metanólise até o décimo ciclo. Trabalhos recentes com o mesmo fungo foram realizados por diversos autores, seja comparando a produção do biodiesel por lipase imobilizada ou livre, seja confrontando a eficácia de células íntegras e da lipase produzida (ambas imobilizadas) (ZENG et al., 2006; LI; DU; LIU, 2007; TAMALAMPUDI et al., 2008). 
Royon e colaboradores (2007) utilizaram óleo de semente de algodão para a produção de biodiesel através de lipase imobilizada de Candida antarctica (comercialmente disponível). Após 24h de reação $\left(50{ }^{\circ} \mathrm{C}\right.$ ), obteve-se $97 \%$ do éster formado, quando a mistura reacional para cada grama do óleo vegetal continha: $32,5 \%$ de t-butanol, $13,5 \%$ de metanol, $54 \%$ do óleo e $0,017 \mathrm{~g}$ de enzima. A estabilidade operacional da catálise no processo contínuo foi testada para a mesma mistura e foi alcançada uma produtividade de $4 \mathrm{~g} / \mathrm{h} /(\mathrm{g}$ da enzima) do referido éster.

Hernández-Martín; Otero (2008) estudaram a síntese enzimática do biodiesel via alcoólise para diferentes óleos vegetais (girassol, oliva, soja e borragem) e utilizaram as lipases comerciais Novozym ${ }^{\circledR} 435$ (Candida antarctica) e Lipozyme ${ }^{\circledR}$ TL IM (Thermomyces lanuginosus). As duas lipases converteram após 48h (Novozym ${ }^{\circledR}$ 435) e $96 \mathrm{~h}$ (Lipozyme ${ }^{\circledR}$ TL IM), 84\% da reação para éster etílico. Os autores optaram pela enzima Novozym ${ }^{\circledR}$ 435, uma vez que após nove ciclos num reator tipo batelada $\left(25^{\circ} \mathrm{C}\right)$, a lipase ainda apresentava $85 \%$ da atividade inicial.

O motivo principal da transesterificação química ser utilizada atualmente em detrimento da enzimática é o custo elevado das lipases. Também existem outros fatores, como a inibição da enzima pelo álcool e o glicerol, presentes na mistura de reação. Dentre os alcoóis que podem ser utilizados nos processos estão o metanol, etanol, isopropanol e butanol, sendo os dois primeiros os mais comuns, em virtude do baixo custo e da disponibilidade. As lipases descritas como mais resistentes aos alcoóis no processo catalítico são as de Rhizomucor miehei, Rhizopus oryzae, Candida Antarctica, Pseudomonas cepacia, além da lipase psicrofílica de Photobacterium lipolyticum (SALIS et al., 2005; RANGANATHAN; SRINIVASAN; MUTHUKUMAR, 2008; YANG; SOHN; KIM, 2009).

\section{Perspectivas futuras}

Os custos para o emprego de lipases em indústrias ainda é elevado, sendo que estas enzimas devem ser ativas e estáveis em $\mathrm{pH}$, temperatura, solventes, e condições específicas otimizadas para cada processo. Uma opção para diminuir os custos está no uso de lipases imobilizadas, que dependerá do desenvolvimento de técnicas e materiais apropriados, mantendo as propriedades cinéticas específicas destas enzimas, ou ainda a imobilização das próprias células microbianas íntegras. Alternativas estariam vinculadas a engenharia genética, embora, paralelamente, não devam ser preteridas às técnicas de isolamento e seleção de cepas microbianas selvagens, dada a vasta biodiversidade existente, que certamente fornecerá micro-organismos que possuam lipases com as características desejadas para uso nos diversos processos biotecnológicos.

\section{Agradecimentos}

Os autores agradecem ao CNPq, Fundação Araucária do Paraná e CAPES pelo apoio financeiro. Bruna Z. da Costa agradece ao CNPq pela bolsa ICPIBIC/UEL.

\section{Referências}

AÇIKEL, Ü.; ERŞAN, M.; AÇIKEL, Y. S. Optimization of critical medium components using response surface methodology for lipase production by Rhizopus delemar. Food and Bioproducts Processing, Rugby, v. 88, p. 3139, 2010.

ALIM, M. A; LEE, J.-H.; SHIN, J.-A.; LEE, Y. J.; CHOI, M.-S.; AKOH, C. C.; LEE, K.-T. Lipase-catalyzed production of solid fat stock from fractionated rice bran oil, palm stearin, and conjugated linoleic acid by response surface methodology. Food Chemistry, London, v. 106, p. 712-719, 2008.

BAJAJ, A.; LOHAN, P.; JHA, P. N.; MEHROTRA, R. Biodiesel production through lipase catalyzed transesterification: An overview. Journal of Molecular Catalysis B: Enzymatic, Amsterdam, v. 62, p. 9-14, 2010.

BECKER, S.; THEILE, S.; HEPPELER, N.; MICHALCZYK, A.; WENTZEL, A.; WILHELM, S.; 
JAEGER, K. E.; KOLMAR, H. A generic system for the Escherichia coli cell-surface display of lipolytic enzymes. FEBS Letters, Amsterdam, v. 579, p. 1177$1182,2005$.

BEISSON, F.; TISS, A.; RIVIERE, C.; VERGER, R. Methods for lipase detection and assay: a critical review. European Journal of Lipid Science and Technology, Weinheim, v. 102, p. 133-153, 2000.

BIANCHI, V. L.; MORAES, I. O.; CAPALBO, D. M. F. Fermentação em estado sólido. In: LIMA, U. A.; AQUARONE, E.; BORZANI, W.; SCHMIDELL, W (Org.). Biotecnologia industrial. São Paulo: Edgard Blücher, 2001. v. 3. p. 264.

BIER, M. Lipases. Methods in Enzymology, New York, v. 1, p. 627-642, 1955.

BÓDALO, A.; BASTIDA, J.; MÁXIMO, M. F.; MONTIEL, M. C.; GÓMEZ, M.; ORTEGA, S. Screening and selection of lipases for the enzymatic production of polyglycerol polyricinoleate. Biochemical Engineering Journal, Amsterdam, v. 46, p. 217-222, 2009.

BOUTAIBA, S.; BHATNAGAR, T.; HACENE, H.; MITCHELL, D. A.; BARATTI, J. C. Preliminary characterization of a lipolytic activity from an extremely halophilic archeon, Natronococcus sp. Journal of Molecular Catalysis B: Enzymatic, Amsterdam, v. 41, p. 21-26, 2006.

BRADY, L.; BRZOZOWSKI, A. M.; DEREWENDA, Z. S.; DODSON, E.; DODSON, G.; TOLLEY, S.; TURKENBURG, J. P.; CHRISTIANSEN, L.; HUGEJENSEN, B.; NORSKOV, L.; THIM, L.; MENGE, U. A serine protease triad forms the catalytic centre of a triacylglycerol lipase. Nature, London, v. 343, p. 767770, 1990.

BRASIL. Ministério de Minas e Energia. Forte crescimento da produção de biodiesel. Boletim mensal dos combustiveis renováveis, Brasília, n. 37, mar. 2010.

BROCKMAN, H. L. General features of lipolysis: reaction scheme, interfacial structure and experimental approaches. In: BORGSTROM, B.; BROCKMAN, H. L. (Ed.). Lipases. Amsterdam: Elsevier Science Publishers, 1984. p. 1-46.

BROZZOLI, V.; CROGNALE, S.; SAMPEDRO, I.; FEDERICI, F.; D'ANNIBALE, A.; PETRUCCIOLI, M. Assessment of olive-mill wastewater as a growth medium for lipase production by Candida cylindracea in bench-top reactor. Bioresource Technology, Essex, v. 100, p. 3395-3402, 2009.

BURKET, J. F. M.; MAUGERI, F.; RODRIGUES, M. I. Optimization of extracellular lipase production by
Geotrichum sp. using factorial design. Bioresource Technology, Essex, v. 91, p. 77-84, 2004.

BUSSAMARA, R.; FUENTEFRIA, A. M.; OLIVEIRA, E. S.; BROETTO, L.; SIMCIKOVA, M.; VALENTE, P.; SCHRANK, A.; VAINSTEIN, M. H. Isolation of a lipase-secreting yeast for enzyme production in a pilotplant scale batch fermentation. Bioresource Technology, Essex, v. 101, p. 268-275, 2010.

CAMMAROTA, M. C.; FREIRE, D. M. G. A review on hydrolytic enzymes in the treatment of wastewater with high oil grease content. Bioresource Technology, Essex, v. 97, p. 2195-2210, 2006.

CARVALHO, P. O.; CAMPOS, P. R. B.; NOFFS, M. D.; OLIVEIRA, J. G.; SHIMIZU, M. T.; SILVA, D. M. Aplicação de lipases microbianas na obtenção de concentrados de ácidos graxos poliinsaturados. Química Nova, São Paulo, v. 26, p. 75-80, 2003.

CASTILHO, L. R.; POLATO, C. M. S.; BARUQUE, E. A.; SANT'ANA JUNIOR., G. L.; FREIRE, D. M. G. Economic analysis of lipase production by Penicillium restrictum in solid-state and submerged fermentations. Biochemical Engineering Journal, Amsterdam, v. 4, p. 239-247, 2000.

CHAHINIAN, H.; VANOT, G.; IBRIK, A.; RUGANI, N.; SARDA, L.; COMEAU, L. C. Production of extracellular lipases by Penicillium cyclopium purification and characterization of a partial acylglycerol lipase. Bioscience, Biotechnology and Biochemistry, Tokyo, v. 64, n. 2, p. 215-222, 2000.

CHANDER, H.; BATISH, V. K.; GHODEKAR, D. R.; SRINIVASAN, R. A. Factors affecting lipase production in Rhizopus nigricans. Journal of Dairy Science, Champaign, v. 64, n. 2, p. 193-196, 1981.

COMMÉNIL, P.; BELINGHERI, L.; BAUW, G.; DEHORTER, B. Molecular characterization of a lipase in Botrytis cinerea by components of grape berry cuticle. Physiological and Molecular Plant Pathology, London, v. 55, p. 37-43, 1999.

CORDOVA, J.; NEMMAOUI, M.; ISMAÏLI-ALAOUI, M.; MORIN, A.; ROUSSOS, S.; RAIMBAULT, M.; BENJILALI, B. Lipase production by solid state fermentation of olive cake and sugar cane bagasse. Journal Molecular Catalysis B: Enzymatic, Amsterdam, v. 5, p. 75-78, 1998.

COSTAS, M.; DEIVE, F. J.; LONGO, M. A. Lipolytic activity in submerged cultures of Issatchenkia orientalis. Process Biochemistry, London, v. 39, p. 2109-2114, 2004.

CÔTÉ, A.; SHARECK, F. Cloning, purification and 
characterization of two lipases from Streptomyces coelicolor A3(2). Enzyme and Microbial Technology, New York, v. 42, p. 381-388, 2008.

CYGLER, M.; SCHRAG, J. D. Structure as basis for understanding interfacial properties of lipases. Methods in enzymology Lipases, Part A: Biotechnology, New York, v. 284, p. 3-27, 1997.

DALMAU, E.; MONTESINOS, J. L.; LOTTI, M.; CASAS, C. Effect of different carbon sources on lipase production by Candida rugosa. Enzyme and Microbial Technology, New York, v.26, p. 657-663, 2000.

DI LUCCIO, M.; CAPRA, F.; RIBEIRO, N. P.; VARGAS, G. D. L. P.; FREIRE, D. M. G.; DE OLIVEIRA, D. Effect of temperature, moisture and carbon supplementation on lipase production by solid-state fermentation of soy cake by Penicillium simplicissimum. Applied biochemistry and biotechnology, Clifton, v. 113, p. 173-180, 2004.

DIAZ, J. C. M.; RODRÍGUEZ, J. A.; ROUSSOS, S.; CORDOVA, J.; ABOUSALHAM, A.; CARRIERE, F.; BARATTI, J. Lipase from the thermotolerant fungus Rhizopus homothallicus is more thermostable when produced using solid state fermentation than liquid fermentation procedures. Enzyme and Microbial Technology, New York, v. 39, p. 1042-1050, 2006.

DOMÍNGUEZ, A.; COSTAS, M.; LONGO, M. A.; Sanromán, A. A novel application of solid state culture: production of lipases by Yarrowia lipolytica. Biotechnology Letters, Dordrecht, v. 25, p. 1225-1229, 2003.

DÜBEREINER, J.; BALDANI, V. L. D. Novas tecnologias biocombustíveis. Revista de Biotecnologia, Ciência e Desenvolvimento, Brasil, v. 1, p. 16-17, 1998.

EDWINOLIVER, N. G.; THIRUNAVUKARASU, K.; NAIDU, R. B.; GOWTHAMAN, M. K.; NAKAJIMA KAMBE, T.; KAMINI, N. R. Scale up of a novel trisubstrate fermentation for enhanced production of Aspergillus niger lipase for tallow hydrolysis. Bioresource Technology, Essex, v. 101, p. 6791-6796, 2010.

ESSAMRI, M.; DEYRIS, V.; COMEAU, L. Optimization of lipase production by Rhizopus oryzae and study on the stability of lipase activity in organic solvents. Journal of Biotechnology, Amsterdam, v. 60, p. 97-103, 1998.

FERNANDES, M. L. M.; KRIEGER, N.; BARON, A. M.; ZAMORA, P. P.; RAMOS, L. P.; MITCHELL, D. A. Hydrolysis and synthesis reactions catalysed by Thermomyces lanuginosa lipase in the AOT/isooctane reversed micellar system. Journal of Molecular Catalysis B: Enzymatic, Amsterdam, v. 30, p. 43-49, 2004.

FERNANDES, M. L. M.; SAAD, E. B.; MEIRA, J. A.; RAMOS, L. P.; MITCHELL, D. A.; KRIEGER, N.
Esterification and transesterification reactions catalysed by addition of fermented solids to organic reaction media. Journal of Molecular Catalysis B: Enzymatic, Amsterdam, v. 44, p. 8-13, 2007.

FERREIRA, V. P. A.; FERREIRA, W. M.; SALIBA, E. O. S.; TEIXEIRA, A. O. Reatividade in vitro de lipase submetida a diferentes tratamentos tecnológicos. Arquivo Brasileiro de Medicina Veterinária e Zootecnia, Belo Horizonte, v. 57, p. 340-344, 2005.

GHALY, A. E.; DAVE, D.; BROOKS, M. S.; BUDGE, S. Production of biodiesel by enzymatic transesterification: review. American Journal of Biochemistry and Biotechnology, New York, v. 6, p. 54-76, 2010.

GOMBERT, A. K.; PINTO, A. L.; CASTILHO, L. R.; FREIRE, D. M. G. Lipase production by Penicillium restrictum in solid-state fermentation using babassu oil cake as substrate. Process Biochemistry, London, v. 35, p. 85-90, 1999.

GOPINATH, S. C. B.; HILDA, A.; PRIYA, T. L.; ANNADURAI, G. Purification of lipase from Cunninghamella verticilata and optimization of enzyme activity using response surface methodology. World Journal of Microbiology \& Biotechnology, Oxford, v. 18, p. 449-458, 2002.

GULATI, R.; ISAR, J.; KUMAR, V.; PRASAD, A. K.; PARMAR, V. S.; SAXENA, R. K. Production of a novel alkaline lipase by Fusarium globulosum using neem oil, and its applications. Pure and Applied Chemistry, Oxford, v. 77, p. 251-262, 2005.

GULATI, R.; SAXENA, R. K.; GUPTA, R. Fermentation and downstream processing of lipase from Aspergillus terreus. Process Biochemistry, London, v. 36, p. 149-155, 2000.

GULATI, R.; SAXENA, R. K.; GUPTA, R.; YADAV, R. P.; DAVIDSON, W. S. Parametric optimization of Aspergillus terreus lipase production and its potential in ester synthesis. Process Biochemistry, London, v. 35, p. 459-464, 1999.

GUPTA, R.; RATHI, P.; GUPTA, N.; BRADOO, S. Lipase assays for conventional and molecular screening: an overview. Biotechnology and Applied Biochemistry, Duluth, v. 37, p. 63-71, 2003.

GUTARRA, M. L. E.; GODOY, M. G.; CASTILHO, L. R.; FREIRE, D. M. G. Inoculum strategies for Penicillium simplicissimum lipase production by solidstate fermentation using a residue from the babassu oil industry. Journal of Chemical Technology and Biotechnology, Oxford, v. 82, p. 313-318, 2007.

HAMA, S.; YAMAJI, H.; FUKUMIZU, T.; NUMATA, T.; TAMALAMPUDI, S.; KONDO, A.; NODA, H.; 
FUKUDA, H. Bioediesel-fuel production in a packedbed reactor using lipase-producing Rhizopus oryzae cells immobilized within biomass support particles. Biochemical Engineering Journal, Amsterdam, v. 34, p. 273-278, 2007.

HASAN, F.; SHAH, A. A.; HAMEED, A. Industrial applications of microbial lipases. Enzyme and Microbial Technology, New York, v. 39, p. 235-251, 2006.

HASAN, F.; SHAH, A. A.; HAMEED, A. Methods for detection and characterization of lipases: A comprehensive review. Biotechnology Advances, New York, v. 27, p. 782-798, 2009.

HEGEDUS, D. D.; KHACHATOURIANS, G. G. Production of an extracellular lipase by Beauveria bassiana. Biotechnology Letters, Dordrecht, v. 10, p. 637-342, 1988.

HERNÁNDEZ-MARTÍN, E.; OTERO, C. Different enzyme requirements for the synthesis of biodiesel: Novozym ${ }^{\circledR} 435$ and Lipozyme $\AA$ TL IM. Bioresource Technology, Essex,v. 99, p. 277-286, 2008.

HOLMQUIST, M. Alpha/beta - hidrolases fold enzymes: structures, functions and mechanisms. Current protein \& peptide science, Hilversum, v. 1, n. 2, p. 209-235, 2000.

HOTTA, Y.; EZAKI, S.; ATOMI, H.; IMANAKA, T. Extremely stable and versatile carboxylesterase from a hyperthermophilic Archaeon. Applied and Environmental Microbiology, Washington, v. 68, p. 3925-3931, 2002.

HOUDE, A.; KADEMI, A.; LEBLANC, D. Lipases and Their Industrial Applications: An Overview. Applied Biochemistry and Biotechnology, Clifton, v. 118, p. 155170, 2004.

IYER, P. V.; ANANTHANARAYAN, L. Enzyme stability and stabilization-Aqueous and non-aqueous environment. Process Biochemistry, London, v. 43, p. 1019-1032, 2008.

JAEGER, K. E.; DIJKSTRA, B. W.; REETZ, M. T. Bacterial biocatalyst: molecular biology, three dimensional structures and biotechnological applications in lipases. Annual Review of Microbiology, Palo Alto, v. 53, p. 315-351, 1999.

JAEGER, K. E.; EGGERT, T. Lipases for biotechnology. Current Opinion in Biotechnology, London, v. 13, p. 390397, 2002.

JAEGER, K. E.; RANSAC, S.; DIJKSTRA, B. W.; COLSON, C.; VAN HEUVEL, M.; MISSET, O. Bacterial lipases. FEMS Microbiology Reviews, Amsterdam, v. 15, p. 29-63, 1994.

JAEGER, K. E.; REETZ, M. T. Microbial lipases form versatile tools for biotechnology. Trends in Biotechnology,
Amsterdam, v. 16, p. 396-403, 1998.

JAEGER, K. E.; SCHNEIDINGER, B.; ROSENAU, F.; WERNER, M.; LANG, D.; DIJKSTRA, B. W.; SCHIMOSSEK K.; ZONTA, A.; REETZ, M. T. Bacterial lipases for biotechnological applications. Journal of Molecular Catalysis B: Enzymatic, Amsterdam, v. 3, p. 3-12, 1997.

JEGANATHAN, J.; NAKHLA, G.; BASSI, A. Hydrolytic pretreatment of oily wastewater by immobilized lipase. Journal of Hazardous Materials, Amsterdam, v. 145, p. 127-135, 2007.

JERMSUNTIEA， W.; AKI， T.; TOYOURA， R.; IWASHITA, K.; KAWAMOTO, S.; ONO, K. Purification and characterization of intracellular lipase from the polyunsaturated fatty acid-producing fungus Mortierella alliacea. New Biotechnology, Amsterdam, v. 28, n. 2, p. 158-164, 2011.

JOSEPH, B.; RAMTEKE, P. W.; THOMAS, G. Cold active microbial lipases: Some hot issues and recent developments. Biotechnology Advances; New York, v. 26, p. 457-470, 2008.

KAMBOUROVA, M.; KIRILOVA, N.; MANDEVA, R.; DEREKOVA, A. Purification and properties of thermostable lipase from a thermophilic Bacillus stearothermophilus MC 7. Journal of Molecular Catalysis B: Enzymatic, Amsterdam, v. 22, p. 307-313, 2003.

KAMINI, N. R.; FUJII, T.; KUROSU, T.; IEFUJI, H. Production, purification and characterization of an extracellular lipase from the yeast, Cryptococcus sp. S-2. Process Biochemistry, London, v. 36, p. 317-324, 2000.

KAMINI, N. R.; MALA, J. G. S.; PUVANAKRISHNAN, R. Lipase production from Aspergillus niger by solidstate fermentation using gingelly oil cake. Process Biochemistry, London, v. 33, p. 505-511, 1998.

KASHMIRI, M. A.; ADNAN, A.; BUTT, B. W. Production, purification and partial characterization of lipase from Trichoderma viride. African Journal of Biotechnology, Victoria Island, v. 5, p. 878-882, 2006.

KEMPKA, A. P.; LIPKE, N. L.; PINHEIRO, T. L. F.; MENONCIN, S.; TREICHEL, H.; FREIRE, D. M. G.; DI LUCCIO, M.; OLIVEIRA, D. Response surface method to optimize the production and characterization of lipase from Penicillium verrucosum in solid-state fermentation. Bioprocess and Biosystems Engineering, Berlin, v. 31, p. 119-125, 2008.

KHATTABI, M.; GELDER, P.; BITTER, W.; TOMAMASSEN, J. Role of the calcium ion and the disulfide bond in the Burkholderia glumae lipase. Journal of Molecular Catalysis B: Enzymatic, Amsterdam, v. 22, 
p. 329-338, 2003.

KOJIMA, Y.; SHIMIZU, S. Purification and characterization of the lipase from Pseudomonas fluorescens HU380. Journal of Bioscience and Bioengineering, Osaka, v. 96, p. 219-226, 2003.

KOUKER, G.; JAEGER, K. E. Specific and sensitive plate assay for bacterial lipases. Applied and Environmental Microbiology, Washington, v. 53, p. 211-213, 1987.

LAYER, P.; KELLER J.; LANKISCH P. G. Pancreatic enzyme replacement therapy. Current Gastroenterology Reports, New York, v. 3, p. 101-8, 2001.

LAYER, P.; KELLER, J. Lipase supplementation therapy: standards, alternatives, and perspectives. Pancreas, New York, v. 26, n. 1, p. 1-7, 2003.

LEE, D. X.; XIA, W. S.; ZHANG, J. L. Enzymatic preparation of chitooligosaccharides by commercial lipase. Food Chemistry, London, v. 111, p. 291-295, 2008.

LI, D.; WANG, B.; TAN, T. Production enhancement of Rhizopus arrhizus by feeding oleic acid. Journal of Molecular Catalysis B: Enzymatic, Amsterdam, v. 43, p. 40-43, 2006.

LI, W.; DU, W.; LIU, D. Optimization of whole cellcatalyzed methanolysis of soybean oil for biodiesel production using response surface methodology. Journal of Molecular Catalysis: B - Enzymatic, Amsterdam, v. 45, p. 122-127, 2007.

LIMA, V. M. G.; KRIEGER, N.; MITCHELL, D. A.; BARATTI, J. C.; FILIPPIS, I.; FONTANA, J. D. Evaluation of the potencial for use in biocatalysis of lipase from a wild strain of Bacillus megaterium. Journal of Molecular Catalysis B: Enzymatic, Amsterdam, v. 31, p. 53-61, 2004.

LIMA, V. M. G.; KRIEGER, N.; SARQUIS, M. I. M.; MITCHELL, D. A.; RAMOS, L. P.; FONTANA, J. D. Effect of the nitrogen and carbon sources on lipase production by Penicillium aurantiogriseum. Food Technology and Biotechnology, Zagreb, v. 41, p. 105110, 2003.

LIN, E.; KO, H. Glucose stimulates production of the alkaline-thermostable lipase of the edible basidiomycete Antrodia cinnamomea. Enzyme and Microbial Technology, New York, v. 37, p. 261-265, 2005.

LIN, E. S.; WANG, C. C.; SUNG, S. C. Cultivating conditions influence lipase production by the edible basidiomycete Antrodia cinnamomea in submerged culture. Enzyme and Microbial Technology, New York, v. 39, p. 98-102, 2006.

LONGHI, S.; CZJZEK, M.; LAMZIN, V.; NICOLAS,
A.; CAMBILlAU, C. Atomic resolution (1.0 ̊̊) cristal structure of Fusarium solani cutinase: stereochemical analysis. Journal of Molecular Biology, London, v. 268, p. 779-799, 1997.

LONGO JÚNIOR, L. S.; BOMBONATO, F. I.; FERRAZ, H. M. C. Métodos de preparação de lactonas de anel médio. Química Nova, São Paulo, v. 30, p. 415424, 2007.

MAHADIK, N. D.; PUNTAMBEKAR, U. S.; BASTAWDE, K. B.; KHIRE, J. M.; GOKHALE, D. V. Production of acidic lipase by Aspergillus niger in solid state fermentation. Process Biochemistry, London, v. 38, p. 715-721, 2002.

MAHANTA, N.; GUPTA, A.; KHARE, S. K. Production of protease and lipase by solvent tolerant Pseudomonas aeruginosa PseA in solid-state fermentation using Jatropha curcas seed cake as substrate. Bioresource Technology, Essex, v. 99, p. 1729-1735, 2008.

MALA, J. G. S.; EDWINOLIVER, N. G.; KAMINI, N. R.; PUVANAKRISHNAN, R. Mixed substrate solid state fermentation for production and extraction of lipase from Aspergillus niger MTCC 2594. Journal of General and Applied Microbiology, Tokyo, v. 53, p. 247-253, 2007.

MALA, J. G. S.; TAKEUCHI, S. Understanding structural features of microbial lipases - An overview. Analytical Chemistry Insights, Auckland, v. 3, p. 9-19, 2008.

MALCATA, F. X.; REYES, H. R.; GARCIA, H. S.; HILL, C. G.; AMUNDSON, C. H. Immobilized lipase reactors for modification of fats and oils - a review. Journal of the American Oil Chemists' Society, Chicago, v. 67, p. 890-910, 1990.

MARCHI, C. E.; BORGES, M. F.; MIZUBUTI, E. S. G. Atividade amilolítica e pectinolítica de Alternaria solani e a relação com a agressividade em tomateiro. Summa Phytopathologica, Jaguariuna, v. 32, p. 345-352, 2006.

MESSIAS, J. M.; COSTA, B. Z.; LIMA, V. M. G.; DEKKER, R. F. H.; REZENDE, M. I.; KRIEGER, N.; BARBOSA, A. M. Screening Botryosphaeria species for lipases: production of lipase by Botryosphaeria ribis EC-01 grown on soybean oil and other carbon sources. Enzyme and Microbial Technology, New York, v. 45, p. 426-431, 2009.

MINISTÉRIO DE MINAS E ENERGIA. Programa Nacional de Produção e Uso de Biodiesel. Disponível em: <http://www.mme.gov.br>. Acesso em: 9 jul. 2010.

MIRANDA, O. A.; SALGUEIRO, A. A.; PIMENTEL, M. C. B.; LIMA FILHO, J. L.; MELO, E. H. M.; DURÁN, N. Lipase production by a brazilian strain of Penicillium citrinum using an industrial residue. Bioresource Technology, Essex, v. 69, p. 145-147, 1999. 
MOSBAH, H.; SAYARI, A.; HORCHANI, H.; GARGOURI, Y. Involvement of Gly 311 residue on substrate discrimination, $\mathrm{pH}$ and temperatura dependency of recombinat Staphylococcus xylosus lipase: A study with emulsified substrate. Protein Expression and Purification, San Diego, v. 55, p. 31-39, 2007.

NGUYEN, L. N.; DAO, T. T.; ŽIVKOVIĆ, T.; FEHRHOLZ, M.; SCHÄFER, W.; SALOMON, S. Enzymatic properties and expression patterns of five extracellular lipases of Fusarium graminearum in vitro. Enzyme and Microbial Technology, New York, v. 46, p. 479-486, 2010.

NIELSEN, P. M.; BRASK, J.; FJERBAEK, L. Enzymatic biodiesel production: technical and economical considerations. European Journal of Lipid Science and Technology, Weinheim, v. 110, p. 692-700, 2008.

NOUREDDINI, H.; GAO, X.; PHILKANA, R. S. Immobilized Pseudomonas cepacia lipase for biodiesel fuel production from soybean oil. Bioresource Technology, Essex, v. 96, p. 769-777, 2005.

OLIVEIRA, M. Biodiesel em ascensão. Disponível em: $<$ http://www.revistapesquisa.fapesp.br $>$. Acesso em: 9 jul. 2010.

PANDEY, A. Solid-state fermentation. Biochemical Engineering Journal, Amsterdam, v. 13, p. 81-84, 2003.

PANDEY, A.; BENJAMIN, S.; SOCCOL, C. R.; NIGAM, P.; KRIEGER, N.; SOCOOL, V. T. The realm of microbial lipases in biotecnology. Biotechnology and Applied Biochemistry, Duluth, v. 29, p. 119-131, 1999.

POKORNY, D.; CIMERMAN, A.; STEINER, W. Aspergillus niger lipases: induction, isolation and characterization of two lipases from a MZKI A116 strain. Journal of Molecular Catalysis B: Enzymatic, Amsterdam, v. 2, p. 215-222, 1997.

PRAZERES, J. N.; CRUZ, J. A. B.; PASTORE, G. M. Characterization of alkaline lipase from Fusarium oxysporum and the effect of different surfactants and detergents on the enzyme activity. Brazilian Journal of Microbiology, São Paulo, v. 37, p. 505-509, 2006.

RANGANATHAN, S. V.; SRINIVASAN, L. N.; MUTHUKUMAR, K. An overview of enzymatic production of biodiesel. Bioresource Technology, Essex, v. 99, p. 3975-3981, 2008.

REIS, P.; HOLMBERG, K.; WATZKE, H.; LESER, M. E.; MILLER, R. Lipases at interfaces: A review. Advances in Colloid and Interface Science, Amsterdam, v. 147-148, p. 237-250, 2009.

REJEB, I. B.; ARDUINI, F.; AMINE, A.; GARGOURI, M.; PALLESCHI, G. Amperometric biosensor based on Prussian Blue-modified screen-printed electrode for lipase activity and triacylglycerol determination. Analytica Chimica Acta, Amsterdam, v. 594, p. 1-8, 2007.

RODRIGUEZ, J. A.; MATEOS, J. C.; NUNGARAY, J.; GONZÁlEZ, V.; BHAGNAGAR, T.; ROUSSOS, S.; CORDOVA, J.; BARATTI, J. Improving lipase production by nutrient source modification using Rhizopus homothallicus cultured in solid state fermentation. Process Biochemistry, London, v. 41, p. 2264-2269, 2006.

ROYON, D.; DAZ, M.; ELLENRIEDER, G.; LOCATELLI, S. Enzymatic production of biodiesel from cotton seed oil using t-butanol as a solvent. Bioresource Technology, Essex, v. 98, p. 648-653, 2007.

RUIZ, C.; BLANCO, A.; PASTOR, F. I. J.; DIAZ, P. Analysis of Bacillus megaterium lipolytic system and cloning of LipA, a novel subfamily I.4 bacterial lipase. FEMS Microbiology Letters, Amsterdam, v. 217, p. 263267, 2002.

SALIS, A.; PINNA, M.; MONDUZZI, M.; SOLINAS, V. Biodiesel production from triolein and short chain alcohols through biocatalysis. Journal of Biotechnology, Amsterdam, v. 119, p. 291-299, 2005.

SARADA, R.; JOSEPH, R. Purification and properties of lipase from the anaerobe Propionibacterium acidipropionici. Journal of the American Oil Chemists' Society, Chicago, v. 69, p. 974-977, 1992.

SARDA, L.; DESNUELLE, P. Action de la lipase pancreátique sur les esteres em emulsion. Biochimica et Biophysica Acta, Amsterdam, v. 30, n. 3, p. 513-521, 1958.

SAXENA, R. K.; DAVIDSON, W. S.; SHEORAN, A.; GIRI, B. Purification and caracterization of an alkaline termostable lipase from Aspergillus carneus. Process Biochemistry, London, v. 39, p. 239-247, 2003.

SCHRAG, J. D.; LI, Y.; WU, S.; CYGLER, M. SerHis-Glu triad forms the catalytic site of the lipase from Geotrichum candidum. Nature, London, v. 351, p. 761764, 1991.

SECUNDO, F.; CARREA, G.; TARABIONO, C.; GATTI-LAFRANCONI, P.; BROCCA, S.; LOTTI, M.; JAEGER, K. E.; PULS, M.; EGGERT, T. The lid is a structural and funcional determinant of lipase activity and selectivity. Journal of Molecular Catalysis B: Enzymatic, Amsterdam, v. 39, p. 166-170, 2006.

SENANAYAKE, S. P. J. N.; SHAHIDI, F. Incorporation of docosahexaenoic acid (DHA) into evening primrose (Oenothera biennis L.) oil via lipase-catalyzed transesterification, Food Chemistry, London, v. 85, p. 
489-496, 2004

SHAH, D. B.; WILSON, J. B. Egg yolk factor of Staphylococcus aureus. Journal of Bacteriology, Washington, v. 89, p. 949-953, 1965.

SHARMA, R.; CHISTI, Y.; BANERJEE, U. C. Production, purification, characterization, and applications of lipases. Biotechnology Advances, New York ,v. 19, p. 627-662, 2001.

SHIN, J.-A.; AKOH, C. C.; LEE, K-T. Enzymatic interesterification of anhydrous butterfat with flaxseed oil and palm stearin to produce low-trans spreadable fat. Food Chemistry, London, v. 120, p. 1-9, 2010.

SIMONS, J-W. F. A.; VAN KAMPEN, M. D.; RIEL, S.; GÖTZ, F.; EGMOND, M. R.; VERHEIJ, H. M. Cloning, purification and characterisation of the lipase from Staphylococcus epidermidis: Comparison of the substrate selectivity with those of other microbial lipases. European Journal of Biochemistry, Berlin, v. 253, p. 675683, 1998.

SINGHANIA, R. R.; PATEL, A. K.; SOCCOL, C. R.; PANDEY,A. Recent advances in solid-state fermentation. Biochemical Engineering Journal, Amsterdam, v. 44, p. 13-18, 2009.

SOMMER, P.; BORMANN, C.; GÖTZ, F. Genetic and biochemical characterization of a new extracellular lipase from Streptomyces cinnamomeus. Applied and Environmental Microbiology, Washington, v. 63, p. 3553-3560, 1997.

STEHR, F.; KRETSCHMAR, M.; KRÖGER, C.; HUBE, B.; SCHÄFER, W. Microbial lipases as virulence factors. Journal of Molecular Catalysis B: Enzymatic, Amsterdam, v. 22, p. 347-355, 2003.

SUN, S. Y.; XU, Y. Membrane-bound 'synthetic lipase' specifically cultured under solid-state fermentation and submerged fermentation by Rhizopus chinensis: a comparative investigation. Bioresource Technology, Essex, v. 100, p. 1336-1342, 2009.

SUN, S. Y.; XU, Y. Solid-state fermentation for 'wholecell synthetic lipase' production from Rhizopus chinensis and identification of the functional enzyme. Process Biochemistry, London, v. 43, p. 219-224, 2008.

SUPAKDAMRONGKUL, P.; BHUMIRATANA, A.; WIWAT, C. Characterization of an extracellular lipase from the biocontrol fungus, Nomuraea rileyi MJ, and its toxicity toward Spodoptera litura. Journal of Invertebrate Pathology, San Diego, v. 105, n. 3, p. 228-235, 2010.

SVENDSEN, A.; SKJOET, M.; YAVER, D.; CHRISTENSEN, L. L. H.; LARSEN, S. E.; LUNDIN, N.; LAMSA M; GREGORY P. C. New lipase, useful for manufacturing a pharmaceutical composition for treating digestive disorders, pancreatic exocrine insufficiency, pancreatitis, cystic fibrosis, or diabetes type I or II. Patent Number(s): WO2008079685-A2, 2008.

SZCZESNA-ANTCZAK, M.; ANTCZAK, T; PIOTROWICZ-WASIAK, M.; RZYSKA, M.; BINKOWSKA, N.; BIELECKI, S. Relationships between lipases and lipids in mycelia of two Mucor strains. Enzyme and Microbial Technology, New York, v. 39, p. 1214-1222, 2006.

TAMALAMPUDI, S.; TALUKDER, M. R.; HAMA, S.; NUMATA, T.; KONDO, A.; FUKUDA, H. Enzymatic production of biodiesel from Jatropha oil: A comparative study of immobilized-whole cell and commercial lipases as a biocatalyst. Biochemical Engineering Journal, Amsterdam, v. 39, p. 185-189, 2008.

TOIDA, J.; FUKUZAWA, M.; KOBAYASHI, G.; ITO, K.; SEKIGUCHI, J. Cloning and sequencing of the triacylglycerol lipase gene of Aspergillus oryzae and its expression in Escherichia coli. FEMS Microbiology Letters, Amsterdam, v. 189, p. 159-164, 2000.

TOM, R. A.; CRISAN, E. V. Assay for lipolytic and proteolytic activity using marine substrates. Applied Microbiology, Washington, v. 29, p. 205-210, 1975.

UL-HAQ, I.; IDRESS, S.; RAJOKA, M. I. Production of lipases by Rhizopus oligosporous by solid-state fermentation. Process Biochemistry, London, v. 37, p. 637-641, 2002.

UPRITCHARD， J. E.; ZEELENBERG， M. J.; HUIZINGA, H.; VERSCHUREN, P. M.; TRAUTWEIN, E. A. Modern fat technology: what is the potential for heart health? Proceedings of the Nutrition Society, Cambridge, v. 64, p. 379-386, 2005.

VERGER, R. Interfacial activation of lipases: facts and artifacts. Trends in Biotechnology, Amsterdam, v. 15, p.32-38, 1997.

VILLENEUVE, P.; MUDERHWA, J. M.; GRAILLE, J.; HAAS, M. J. Customizing lipases for biocatalysis: a survey of chemical, physical and molecular biological approaches. Journal of Molecular Catalysis B: Enzymatic, Amsterdam, v. 9, p. 113-148, 2000.

WARNER, J. C.; CANNON, A. S.; DYE, K. M. Green Chemistry. Environmental Impact Assessment Review, New York, v. 24, p. 775-799, 2004.

WINKLER, F. K.; D'ARCY, A.; HUNZIKER, W. Structure of human pancreatic lipase. Nature, London, v. 343, p. 771-774, 1990.

WINKLER, U. K.; STUCKMANN, M. Glycogen, hyaluronate, and some other polysaccharides greatly 
enhance the formation of exolipase by Serratia marcescens. Journal of Bacteriology, Washington, v. 3, p. 663-670, 1979.

WOLSKI, E.; MENUSI, E.; REMONATTO, D.; VARDANEGA, R.; ARBTER, F.; RIGO, E.; NINOW, J.; MAZUTTI, M. A.; DI LUCCIO, M.; OLIVEIRA, D.; TREICHEL, H. Partial characterization of lipases produced by a newly isolated Penicillium sp. in solid state and submerged fermentation: A comparative study. LWT -Food Science and Technology, London, v. 42, p. 1557-1560, 2009.

YANG, K. S.; SOHN, J-H.; KIM, H. K. Catalytic properties of a lipase from Photobacterium lipolyticum for biodiesel production containing a high methanol concentration. Journal of Bioscience and Bioengineering, Osaka, v. 107, p. 599-604, 2009.

YOO, H-Y.; SIMKHADA, J. R.; CHO, S. S.; PARK, D. H.; KIM, S. W.; SEONG, C. N.; YOO, J. C. A novel alkaline lipase from Ralstonia with potential application in biodiesel production. Bioresource Technology, Essex, v. 102, p. 6104-6111, 2011.

YOSHIDA, F.; MOTAI, H.; ICHISHIMA, E. Effect of lipid materials on the production of lipase by Torulopsis ernobii. Applied Microbiology, Washington, v. 16, p. 845-847, 1968.

ZENG, J.; DU, W.; LIU, X.; LIU, D.; DAI, L. Study on the effect of cultivation parameters and pretreatment on Rhizopus oryzae cell-catalyzed transesterification of vegetable oils for biodiesel production. Journal of Molecular Catalysis: B - Enzymatic, Amsterdam, v. 43, p. 15-18, 2006.

ZENG, X.; XIAO, X.; WANG, P.; WANG, F. Screening and characterization of psychrotrophic, lipolytic bacteria from deep-sea sediments. Journal of Microbiology and Biotechnology, Oxford, v. 14, p. 952-958, 2004.

Recebido em 2 Abril 2011-Received on April 2, 2011.

Aceito em 31 Agosto, 2011 - Accepted on August 31, 2011. 
